\title{
Expansión urbana, conflictos sociales y deterioro ambiental en la ciudad de México. El caso del Ajusco
}

\section{Martha Schteingart*}

\begin{abstract}
Este ensayo se enfoca al análisis y vinculación de los aspectos sociales y fisico-ambientales del crecimiento urbano tomando como caso la Zona Metropolitana de la Ciudad de México. Para ello se exponen las caracteristicas generales del crecimiento y la expansión fisica de la ciudad asi como sus consecuencias sobre el medio ambiente. Para explicar los conflictos sociales que dan sustento a esos fenómenos y ejemplificar la diversidad de procesos y agentes sociales que determinan la configuración de la relación ciudad-medio ambiente, se estudia la zona del Ajusco. Se señalan las características fisicas y el poblamiento de la zona, los conflictos sociales que existian antes de la expansión urbana y los provocados por la creciente urbanización; se muestra la vinculación entre ambas etapas, la permanencia de ciertos enfrentamientos y la aparición de nuevos, destacando la concurrencia de múltiples factores determinantes de la problemática ambiental El análisis se basa en investigaciones anteriores propias $y$ de otros investigadores $y$ en un reciente trabajo de campo sobre la zona
\end{abstract}

\section{Introducción}

La ciudad es el medio socio-espacial en el que las actividades alli asentadas y el modo específico en que se aglomeran los elementos que las constituyen, reproducen la vida material del hombre y las relaciones sociales del modo de producción dominante.

Los procesos económicos y sociales incluidos en la producción, el consumo y el intercambio, base de la reproducción social, tienen, por su parte, una especialidad concreta. Requieren de una base material que se organizará en el territorio, siguiendo la lógica particular de la producción del marco construido, en la que están implicados distintos agentes sociales.

Aquellos procesos y la producción de su base material, traen aparejada una apropiación de la naturaleza, a través de la utilización de recursos naturales, que impactan el medio ambiente de la ciudad. Ellos también generan residuos y deshechos que afectan la calidad del aire, el agua y el suelo del medio urbano y su entorno.

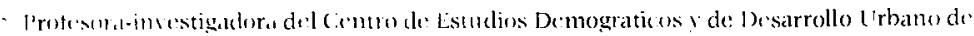

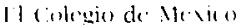

Este: trabajo fue: realizado con la colaboracion de: Rosario Guzman como alsistente: de investigacion. Agradecemos ademas la informacion aportada por colonos de las colonias populares del Ajusco, ejidatarios de San Nicolis Totolapan, estudiantes y protesores de biologia, arquitectura y trabajo social de la 1 xim. el Grupo de: Tecnologia Alternativa y la Comision Coordinadora palral el Desarrollo Agropecuario del D.F. 
La ciudad es, entonces, desde el punto de vista de su interacción con el medio ambiente, importadora de energía, transformadora de la misma para ser exportada o consumida localmente, utilizadora del medio "natural" inmediato (que sirve de soporte físico a la producción del marco construido) y el lugar donde se evacúan residuos de distinto tipo (Ibarra, Puente, Schteingart, 1984).

En particular, las formas que asumirá la destrucción del medio "natural" o productivo (bosques, áreas cultivadas, etc.) por el medio construido de la ciudad, dependerá de las características físicas y sociales de los espacios circundantes, del ritmo de la expansión urbana, y de las formas de producción del marco construido, en el contexto de las diferentes coyunturas socio-políticas en las que se dan estos procesos.

El trabajo que presentaremos a continuación se centrará justamente en el análisis de este último aspecto de la interacción ciudadmedio ambiente, tomando como caso de estudio la Zona Metropolitana de la Ciudad de México (zмcm).

Para desarrollar este trabajo, comenzaremos por exponer las características generales del crecimiento y la expansión física de la ciu$\mathrm{dad}$, así como sus consecuencias sobre el territorio inmediato y, en particular, sobre tierras de uso agrícola y forestal, sobre la degradación de los suelos y el equilibrio ecológico.

Pero para referirnos de manera más específica a los conflictos sociales que están detrás de esos fenómenos y para poder ejemplificar la diversidad de procesos y agentes sociales que entran en la configuración de la relación ciudad-medio ambiente, presentaremos en la segunda parte del estudio un análisis de la Zona del Ajusco.

Este hará referencia a las características geográficas y al poblamiento de la zona, así como a los conflictos sociales que existieron antes de la expansión urbana o que fueron provocados por la urbanización reciente; se mostrarán las vinculaciones entre ambas etapas, la permanencia de ciertos enfrentamientos y la aparición de nuevos, poniendo en evidencia la determinación de la problemática ambiental por la multiplicidad de factores considerados.

Hemos elegido la Zona del Ajusco porque debido a sus condiciones naturales, a la importancia que tiene para el "equilibrio ecológico" de la ciudad de México, a los movimientos sociales urbanos que allí se han generado, y a las políticas que ha intentado aplicar el Estado, se constituye en un caso ejemplar dentro de la zмсм.

Esta presentación se apoya en nuestras propias investigaciones anteriores, en estudios realizados por otros investigadores, y en un trabajo de campo sobre la Zona del Ajusco que hemos llevado a cabo recientemente; este ha incluido entrevistas a los agentes socia- 
les implicados, así como la revisión de archivos y documentos especiales.

II. Aspectos generales del crecimiento de la ciudad de México y su impacto ambiental

\section{Expansión urbana y estructuración social del espacio}

La ciudad de México comienza su proceso de industrialización y de gran crecimiento poblacional en los años cuarenta. Este se ha acompañado de una gran expansión física y del surgimiento de nuevas actividades y grupos sociales urbanos, conformándose así áreas diferenciadas por sus ventajas locacionales, sus estructuras fisicas y su nivel de servicios y equipamientos.

La Zona Metropolitana comprende actualmente todas las delegaciones del Distrito Federal y un amplio conjunto de municipios del Estado de México, habiendo pasado de 1670314 habitantes en 1940 a 13445000 en 1980 , con altas tasas de crecimiento anual y una fuerte incidencia de las migraciones sobre el crecimiento total (cuadro 1).

Asimismo, se ha producido una gran expansión del área urbana que cubría unas 11700 hectáreas en 1940 y alrededor de 100000 hectáreas en 1980. De 1525 a 1953 (430 años) la ciudad aumentó su superficie en 24000 hectáreas; de 1953 a 1980 (27 años) ese aumento fue de aproximadamente 43000 hectáreas. (Comisión Coordinadora para Desarrollo Agropecuario del D.F., 1982). Es decir que el área urbana se incrementó cerca de nueve veces entre 1940 y 1980, incluyendo la creciente descentralización de las actividades productivas, comerciales y de servicios, así como la suburbanización de diferentes grupos sociales.

El cuadro 1, muestra claramente ese proceso de suburbanización. En 1950, sólo 1\% de la población metropolitana vivía en el Estado de México mientras en 1980 ella alcanza 35\% del total. Por el contrario en 1950 las delegaciones centrales concentraban $75.7 \%$ de la población y en 1980 sólo 19.5 por ciento.

La expansión territorial de la ciudad de México se ha producido con características muy particulares en cuanto a las formas de tenencia de la tierra rural que ha ocupado, situación que diferencia notablemente a México de otros países latinoamericanos. Desde la época prehispánica, y sobre todo desde el periodo colonial, pasando por las diferentes etapas posteriores de la historia mexicana, han coexistido en este país la propiedad privada y colectiva del suelo, en las que están implicados diferentes grupos sociales, cuyos en- 


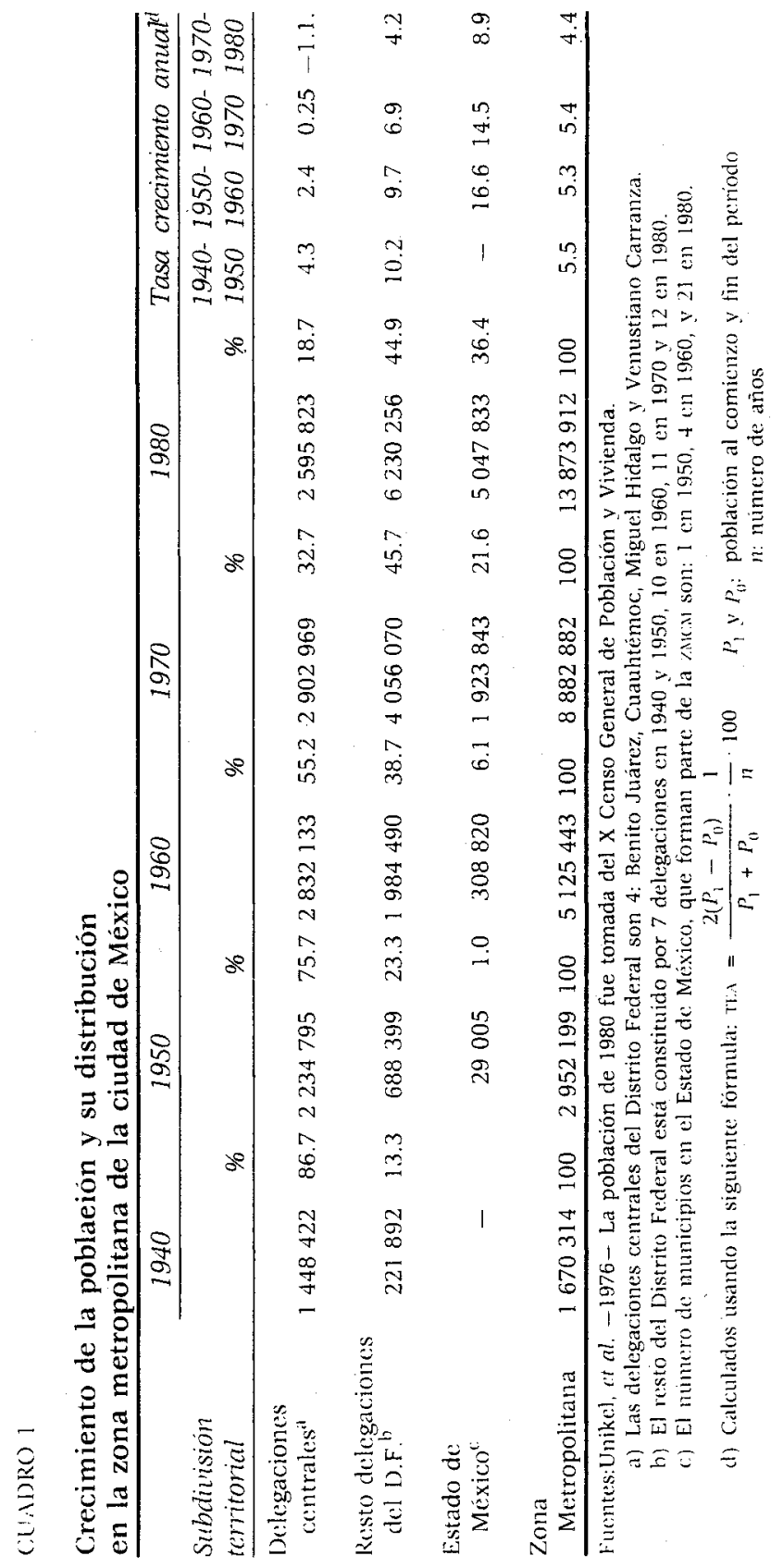


frentamientos han dado origen a frecuentes conflictos, muchas veces violentos.

La forma de propiedad y explotación de tipo colectivo se dio entonces, en el periodo precolonial y durante la Colonia. ${ }^{1}$ La reforma agraria, a partir de 1915 volvió a establecer el sistema de ejidos, habiéndose fijado, especificado y modificado luego sus características, a través de diferentes normas legales. ${ }^{2}$

Si bien la reforma agraria fue puesta en práctica plenamente en el país durante la administración cardenista, en el territorio del Distrito Federal ella comenzó antes, habiéndose dotado la mayoría de los ejidos en los años veinte. Así, en esa administración se repartió sólo una tercera parte de la superficie ejidal que se había repartido hasta 1934; se crearon 8 ejidos más y se ampliaron 23 , los que contribuyeron con $23.4 \%$ del total de hectáreas distribuidas en el D.F. (Cruz, M.S., 1981). Parecería ser entonces que con Cárdenas sólo culmina la formación de la propiedad ejidal urbana, con consecuencias particulares sobre el proceso de urbanización que se aceleró más tarde.

La tierra de las comunidades agrarias (comunal y ejidal) afectó cuantitativamente la expansión de la mancha urbana de la siguiente manera:

a) En el D.Fi, entre 1940 y 1975, ese crecimiento se produjo en $52.8 \%$ sobre propiedad privada, en $26.5 \%$ sobre tierra comunal, y en $20.7 \%$ sobre propiedad ejidal. Así, un poco menos de la mitad del crecimiento urbano se dio sobre terrenos de las comunidades agrarias. De 75 ejidos existentes en 1938, aproximadamente 24 permanecieron intactos, 37 han desaparecido y 14 están ocupados parcialmente por usos urbanos. En el futuro, la expansión urbana se dará principalmente sobre terrenos comunales, que dominan al sur del D.F.

b) En el Estado de México, la mancha urbana creció $21.9 \%$ sobre tierra ejidal, $27.5 \%$ sobre tierra comunal, $27.8 \%$ sobre tierra de propiedad directa del Estado (producto de la desecación del lago de Texcoco) y sólo $22.8 \%$ sobre tierra privada. Estas proporciones demuestran claramente que la ciudad se expandió sobre tierras no privadas

\footnotetext{
1 En la época precolonial, a través de los "calpulli" de los aztecas, y durante la Colonia, a través de los ejidos de los pueblos (tierras comunales que se encontraban a la salida de éstos y servian para el ganado, recolección de madera, etcétera).

2 La tenencia ejidal por parte de los núcleos agrarios permite a los campesinos apropiarse únicamente del producto obtenido de trabajar esos terrenos, quedando prohibida la enajenación de los mismos; los terrenos sólo pueden ser expropiados por causa de utilidad pública o interés social, según lo establece la legislación agraria.
} 
en una medida mucho mayor que en el Distrito Federal ( $77 \%$ de la mancha urbana se expandió sobre tierras de carácter público o colectivo). Si se tienen en cuenta las proporciones de diferentes tipos de propiedad existentes en los municipios aún no urbanizados, podría afirmarse que en el futuro el crecimiento en el Estado de México se daría sobre todo en la propiedad ejidal y comunal.

En general, las diferentes formas de transformación de las tierras ejidales y comunales a usos urbanos, dependen de la utilización final de las mismas (para qué actividad, para qué sector social) así como de los agentes y mecanismos intervinientes, que pueden ubicarse dentro o fuera de la legalidad existente. Como parte de las formas legales se han dado las expropiaciones y las permutas (estas últimas sólo hasta 1971) y entre las formas no legales aparecen las invasiones, la venta ilegal de terrenos a los sectores populares y la apropiación ilegal, por parte del capital, a través de empresas inmobiliarias.

Entre 1938 y 1976, la superficie ejidal expropiada para obras de utilidad pública o interés social cubrió un poco más de $60 \%$ de este tipo de propiedad ocupada por la mancha urbana. Esas expropiaciones fueron para la construcción de obras viales, hospitales, escuelas y centros educativos, zonas industriales, así como para el desarrollo de conjuntos habitacionales de interés social. Sin embargo, numerosos fraccionamientos para sectores afluentes de la sociedad se han asentado sobre terrenos ejidales (sobre todo en el Estado de México, violando así los principios establecidos en la Ley de Reforma Agraria). Por ejemplo, en el Estado de México, $40 \%$ de terrenos ejidales fue utilizado para ese tipo de desarrollos (Schteingart, M., 1981a).

En cuanto a la utilización de esos terrenos por colonias populares, las proporciones han ido en aumento, sobre todo en el D.F., mientras que en el Estado de México han ocupado en mayor medida las tierras públicas, originadas en la desecación del lago de Texcoco, donde muchas veces el tipo de propiedad aparece muy confuso (Schteingart, M., 1981b).

Hasta 1960, la ocupación de ejidos por colonias populares no fue mayoritaria, y se daba sobre todo a través del crecimiento natural de los pueblos originarios. Posteriormente, se ha observado que esas colonias constituyen el tipo de uso más generalizado dentro de la urbanización de tierras ejidales, siendo las invasiones y particularmente las ventas ilegales por parte de ejidatarios, las que generan la formación de las mismas (Cruz, M.S., 1981).

Es importante destacar que la existencia de terrenos comunales y ejidales en el área de expansión de la ciudad no sólo afecta 
la formación de nuevos espacios urbanos sino que también origina problemas específicos en las zonas rurales inmediatas - incidiendo de manera particular en los usos del suelo no urbanos que subsisten o se van transformando- y en la población campesina, o la que se encuentra en proceso de integración al medio urbano. Sin embargo, esta perspectiva de análisis del crecimiento urbano ha sido mucho menos atendida, ya que en el estudio de la relación entre lo rural y lo urbano, sobre todo en la franja en que estos dos medios se unen fisicamente y se vinculan más directamente, ha prevalecido mayormente el interés por los problemas de la ciudad.

Algunos de los mecanismos y procesos incluidos dentro de la problemática enunciada, serán analizados con un cierto detalle en el estudio del caso que presentaremos.

\section{Efectos ambientales de la expansión urbana sobre el medio rural circundante}

Aunque se insiste mucho en la disminución de áreas cultivadas, en la degradación de los suelos y en la pérdida de productividad, a raíz de la expansión urbana, los datos que se manejan son aún bastante imprecisos o insuficientes y todavía enormes las lagunas en este campo del conocimiento.

Según estudios realizados por la Comisión Coordinadora para el Desarrollo Agropecuario del D.F. (creada en 1977), los excelentes suelos planos de esa entidad permitieron su utilización agrícola en forma intensiva hasta principios de siglo. Luego ellos fueron ocupados por la ciudad, y la agricultura se trasladó a las zonas altas y bosques.

Existían en el D.F. unas 40000 hectáreas de suelo de primera calidad de las cuales se conservan 1620 hectáreas en Xochimilco y Tláhuac; asimismo en Tlalpan y Milpa Alta existen cerca de 25000 hectáreas de agricultura de temporal que está bajo un fuerte proceso de erosión. La agricultura de temporal ha mantenido la superficie cultivada (alrededor de 30600 hectáreas) entre 1959 y 1984 mientras que la agricultura chinampera, ya muy limitada, se ha reducido casi a la mitad en ese mismo perido (pasando de 2200 a 1300 hectáreas).

En general, la agricultura ocupa $31 \%$ de la superficie de las siete delegaciones del sur del Distrito Federal, siendo los cultivos bajo el régimen de temporal el maíz, la avena y el nopal, y en las chinampas, las hortalizas, las plantas ornamentales, medicinales y condimenticias, además del maíz.

A pesar de que no ha disminuido la superficie de agricultura de temporal, la citada Comisión Coordinadora advierte sobre la utiliza- 
ción inadecuada del suelo, caracterizada por la introducción de asentamientos humanos en tierras de vocación agrícola, lo cual ha provocado el desplazamiento de la agricultura que se establece, como ya dijimos, en zonas antes boscosas. También se señala "el crecimiento de pastizales como parte de la ganadería extensiva mal planeada, en detrimento de suelos agrícolas y forestales" (Programa Rector de Uso del Suelo y Desarrollo Agroforestal, 1985). Existe, por otra parte, un bajo rendimiento de los cultivos, inferior a las medias nacionales.

Los bosques cubren $35 \%$ de la superficie de las mismas siete delegaciones con una extensión de 36000 hectáreas predominando los de pino y de oyamel-pino. La superficie forestal sí ha sufrido un descenso de aproximadamente $15 \%$ en el periodo 1959-1984, pero lo más grave es que el control biológico entre las especies fue alterado, permitiendo el surgimiento y acentuación de plagas. La pérdida de bosques afecta la recarga de acuíferos al sur de la ciudad, que aporta $6 \mathrm{~m}^{3}$ por segundo, es decir $20 \%$ del total de agua que se bombea del subsuelo del Valle de México, para consumo del D.F. De ahi también la importancia ecológica de la Zona del Ajusco.

La información con respecto al Estado de México es mucho más limitada; no se dispone de datos históricos que permitan observar la evolución de la situación con el explosivo crecimiento metropolitano que se dio en esta entidad, mucho mayor que en el D.F.

Los municipios del Estado de México que forman parte de la Zona Metropolitana, tienen mayor importancia agrícola que el D.F. Además de que el porcentaje de terrenos dedicado a actividades agrícolas es superior, la agricultura de riego tiene también mucho más peso.

A pesar de que las proporciones de tierra cultivable son importantes en el valle de México, el producto agrícola y la producción de alimentos para el consumo de la población son relativamente pequeños. El Distrito Federal y los estados de México e Hidalgo, producen fracciones insignificantes del trigo y frijol consumido en ese valle. También es importante señalar que una fracción considerable de la tierra de riego se usa para forrajes, sobre todo alfalfa. En los últimos diez años se ha dado una transformación en la agricultura, al cambiarse la producción de ciertos cultivos para la alimentación humana, por forrajes para el ganado.

Estos hechos, sumados a la baja productividad agrícola en las zonas de temporal, y a la gran cantidad de alimentos necesarios para la enorme población de la ciudad de México, han concurrido para configurar una situación en la que gran parte de los alimentos consumidos se importan de otros lugares y a veces desde grandes distancias (Campbell, 1981). Ello produce un encarecimiento de los 
mismos que se revierte sobre las familias de menores ingresos, las que no pueden acceder a una dieta mínimamente aceptable.

III. La zona del Ajusco

\section{Presentación general y antecedentes del poblamiento de la zona}

La llamada Zóna del Ajusco se encuentra ubicada en el surponiente del D.F. y corresponde a la sierra del mismo nombre, una porción de la cordillera neo-volcánica que forma el límite sur de la cuenca de México, cerrando la antigua comunicación de éste con el valle de Morelos y el río Balsas. La estructura principal de la sierra se formó al final del mioceno y posteriormente aparecieron numerosos volcanes (como el Xitle y el Teutli) los cuales arrojaron lavas basálticas que formaron amplias llanuras de malpaís, como la del Pedregal de San Angel (Comisión Coordinadora para el Desarrollo Agropecuario del D.F., 1980).

En el Ajusco no existen corrientes que puedan clasificarse como ríos, y sólo en la época de lluvias se transforman en arroyos torrenciales. En toda esta región pedregosa, el agua de lluvia se filtra y forma mantos subterráneos que brotan como manantiales en algunos sitios, con aguas muy puras y limpias. Asimismo, ella se ha reservado como Parque Nacional por sus recursos forestales, que incluyen coniferas, árboles de maderas blandas, predominando los pinos y el oyamel (Reyes, A. 1981).

Desde la época prehispánica, en esta zona y en otras áreas del sur del D.F., existieron numerosos pueblos indígenas; ellos fueron provistos de terrenos comunales, durante la Colonia. Pero desde el siglo xvII comenzaron a surgir las haciendas cuya expansión se produjo sobre todo durante el siglo pasado, a costa de las comunidades indigenas.

Por su parte, las industrias de tejidos, hilados y papel, empezaron a desarrollarse a mediados del siglo xix, empleando a pobladores de la zona. Éstos, al perder sus propias tierras, no tuvieron otra alternativa que emplearse como jornaleros en las haciendas, y algunas veces también combinaron las tareas agrícolas con las fabriles, en las industrias locales (Durand, J., 1983).

A raíz de la reforma agraria y, como ya señalamos, durante los años veinte, se produjo la dotación de los ejidos de la zona, a partir de la expropiación de las haciendas. Pero la dotación de ejidos no fue suficiente para satisfacer las necesidades agricolas de los habitantes de los pueblos, básicamente debido a la calidad de las tierras entregadas. En general éstas eran de agostadero (pedregosas, inúti- 
les para la agricultura); una pequeña proporción era de temporal y ninguna de riego.

Por estas razones y como consecuencia además del aumento de la población, se solicitaron las ampliaciones de los ejidos, que se otorgaron principalmente en la administración cardenista, pero que tampoco fueron suficientes para satisfacer las necesidades de los campesinos. A los propietarios de las haciendas y ranchos agrícolas afectados se les reconoció una indemnización, protegiéndose además sus mejores tierras (Lugo y Bejarano, 1981).

Así entonces, en los primeros años del reparto agrario, se mejoró el nivel de vida de los ejidatarios limitándose el proceso de proletarización; pero él no pudo frenarse por mucho tiempo, debido a la extensión y la calidad de las tierras que se repartieron. Con el periodo cardenista terminó el proceso de reforma agraria en esta zona y comenzó también la lenta desintegración de los ejidos.

La explotación forestal fue muy importante para algunos pueblos. Tanto los bosques comunales como ejidales fueron usados en algunos casos para el consumo personal de los campesinos, o para vender la madera en el mercado, y en otros casos se entregaba en concesión a las fábricas de papel Loreto y Peña Pobre. Esto condujo a la depredación de los bosques y en algunos casos se agotaron los recursos de comunidades que dependian en gran medida de la explotación de los mismos (Durand, J., 1981).

\section{El ejido de San Nicolás Totolapan}

\section{Dotación y ampliación del ejido}

Los procesos de formación, utilización y transformación del ejido de San Nicolás Totolapan, sobre el cual se ha producido una parte importante de la urbanización de la zona, nos permitirán profundizar en el conocimiento de los conflictos generados por la tenencia de la tierra, y de sus consecuencias socioambientales.

La descripción se basará principalmente en la información que hemos encontrado en los archivos de la Secretaría de la Reforma Agraria así como en los datos provistos por algunos informantes clave.

Desde mediados del siglo pasado los habitantes del poblado de San Nicolás Totolapan comenzaron a ser despojados de sus tierras por el dueño de la hacienda La Eslava, don Fernando de Teresa "principal acaparador y responsable de la tala inmoderada de los bosques". También los propietarios de las haciendas El Arenal y La Cañada así como la fábrica de hilados La Magdalena invadieron aquellos te- 
rrenos y estas situaciones fueron denunciadas por los pobladores en 1920, cuando recurrieron a la Comisión Nacional Agraria (CNA) para que se les restituyeran sus tierras, amparándose en títulos cedidos por "merced real" en 1536. En 1921, se señalaron nuevos ataques a sus terrenos, sobre todo por la fábrica de tejidos La Hormiga, que utilizaba el agua del río Magdalena como fuerza motriz, habiendo disminuido su caudal, y habiendo agotado además varios manantiales que siempre pertenecieron a ese pueblo.

A pesar de que los acusados se defendieron alegando que sus acciones eran legales y que poseían títulos de propiedad de sus tierras ${ }^{3}$ los demandantes insistieron en la solicitud de restitución de tierras, montes y aguas que les pertenecían.

Resulta interesante resaltar que en una carta enviada al presidente de la Comisión Nacional Agraria del D.F. por la junta de vecinos del pueblo de San Nicolás Totolapan en 1921, se denunciaba la continuación de la abusiva explotación de maderas (a pesar de la orden de suspensión de la tala de montes), la cual provocaba un aflojamiento de las tierras vegetales que serían arrastradas por las 1luvias, perjudicando asi el valor de los terrenos que estaban solicitando. Se afirmaba que frente a la perspectiva de la restitución de esas tierras a sus anteriores propietarios, se habían dejado grandes extensiones como la "palma de la mano", además con fatales consecuencias para el clima de la ciudad de México. El contenido de esta carta muestra que ya en esta época los habitantes de los pueblos y los campesinos veian con claridad los efectos que las acciones depredadoras de los hacendados podrían tener sobre el equilibrio ecológico de la ciudad, produciendo un fuerte deterioro ambiental, temas que serán presentados muchísimo más tarde por el poder público. Por otra parte, es importante resaltar el manejo de todo tipo de recursos por parte de los propietarios que iban a ser afectados, y que empeoraron aún más las condiciones del reparto agrario, ya bastante poco favorables para los supuestos beneficiados.

En 1922, la CNA resolvió que no procedía la restitución de 50000 hectáreas solicitada por el pueblo, alegando que las firmas del virrey en los documentos presentados eran apócrifas, reconociéndose en cambio la autenticidad de los títulos de la hacienda La Eslava. En 1923, se propuso entonces la dotación de tierras a los habitantes del poblado para lo cual se levantó un censo que indicó la existencia de 282 jefes de familia, de los cuales 125 eran obreros, 12 comer-

\footnotetext{
3 Por ejemplo, la familia De Teresa alegó que la hacienda La Eslava fue adquirida en subasta pública en 1783 ; de ahí pasó a propiedad de diferentes personas hasta que en 1865 la adquirió el padre de don Fernando de Teresa.
} 
ciantes, 2 electricistas, 3 empleados, 10 mujeres domésticas y 3 obreras; sólo 111 individuos resultaron sujetos de dotación. De las 1401 hectáreas dotadas, 1198 correspondieron a monte y 101 a tierras de temporal; 1300 hectáreas fueron tomadas de la hacienda La Eslava.

En 1929, los representantes del ejido realizaron una nueva gestión para conseguir la restitución de las tierras, ya que las entregadas eran muy reducidas y en muy pequeña medida servían para la agricultura. Entonces recurrieron al Archivo General de la Nación para obtener copias que legitimaran sus derechos; a pesar de que se reconoció su autenticidad, las autoridades agrarias argumentaron que no era posible revocar una resolución presidencial que negaba esa restitución.

En 1935, se solicitó la ampliación del ejido, a partir de la expropiación de terrenos de las haciendas La Eslava y La Cañada. Antes de la afectación La Eslava tenía 4600 hectáreas; perdió 1300 en la primera dotación a San Nicolás Totolapan y 348 hectáreas en la dotación a San Andrés Totoltepec. En 1973, ella contaba aún con 2952 hectáreas, de las cuales sólo 24 eran de temporal y el resto de agostadero y monte; 400 quedaron como pequeña propiedad y las 2552 restantes se afectarían a la ampliación y dotación de ejidos, de las cuales 1300 le corresponderian a San Nicolás Totolapan. Sin embargo, teniendo en cuenta que una parte del Parque Nacional "Cumbres del Ajusco"4 se encontraba en esa hacienda (son tierras inafectables por decreto presidencial de 1937) deberian excluirse de las afectaciones ejidales ( 1722 hectáreas). Descontada esa superficie, a San Nicolás Totolapan le correspondieron en definitiva sólo 612 hectáreas (y a San Andrés Totoltepec 94 hectáreas). Evidentemente esas tierras fueron muy insuficientes para las necesidades de los pobladores y minimas comparadas con las solicitadas en restitución, las que además hubieran permitido a los campesinos disponer de extensiones más adecuadas para la agricultura.

Las restituciones de tierras no fueron aceptadas por las autoridades en la mayoría de los casos que conocemos, dentro del Distrito Federal.

El relato que hemos presentado confirma algunas tendencias ya señaladas anteriormente y que se han observado tanto en el reparto agrario a nivel del D.F. como más específicamente en el sur de

4 . En 1937 el presidente Cárdenas creó el parque nacional "Cumbres del Ajusco" que comprendía la gran parte de los bosques del sur del D.F. En 1938 se amplió la Reserva de Repoblación Forestal para proteger la totalidad de bosques del D.F. En 1947 el presidente Miguel Alemán expidió un decreto concesionando la explotación de los bosques a las fábricas de papel Loreto y Peña Pobre; con esto se redujeron los linderos de ese parque nacional a 920 hectáreas. (COCODA, 1982). 
esa entidad (momento histórico de las dotaciones; reparto insuficiente de tierras; mala calidad de las mismas, etcétera).

Nos ha permitido también observar cómo se dieron los conflictos entre hacendados y campesinos, no sólo por la tierra sino también por otros recursos naturales como el agua y los bosques, así como el papel que jugó el Estado frente a ciertas demandas campesinas (como las restituciones). Pero quizás uno de los aspectos más significativos que ha surgido del análisis es el que se refiere a la temprana degradación del medio ambiente (muy anterior a la urbanización de la zona) y a las relaciones entre explotación del territorio por agentes propietarios y capitalistas, enfrentamientos sociales frente al reparto agrario y deterioro de los recursos naturales. Veremos cómo continúan o se modifican estas relaciones en la etapa siguiente de desarrollo de la zona en estudio.

\section{La urbanización del ejido}

Después de analizar los antecedentes del poblamiento y la evolución de la tenencia de la tierra, trataremos de observar qué ha ocurrido cuando el crecimiento de la población y la expansión del área urbana comenzaron a presionar sobre la zona. En esta etapa los señalados conflictos entre propietarios rurales y ejidatarios, o habitantes de los pueblos, pasaron a segundo plano (aunque a veces vuelven a actualizarse) apareciendo en la escena suburbana nuevos agentes sociales (fraccionadores, colonos, nuevos organismos públicos encargados del desarrollo de la ciudad) que hacen más complicada la trama de relaciones y provocan al mismo tiempo una diversificación de enfrentamientos así como nuevas situaciones sociales con relación a lo urbano-ambiental.

Como ya lo han señalado algunos estudios (Durand, J., 1983; Lugo y Bejarano, 1981) la ciudad de México creció notablemente hacia el sur en los años cincuenta y sesenta. Obras importantes como la construcción de la Ciudad Universitaria y del periférico, la realización de conjuntos habitacionales promovidos por el Estado (como la Unidad Independencia), indican que la acción pública jugó un papel importante en este crecimiento. También algunas promociones privadas siguieron a la obra pública y entre ellas es necesario mencionar la apertura de los pedregales, como zona residencial para sectores de altos ingresos. El gran aumento de la población de Tlalpan, Magdalena Contreras y Xochimilco en las últimas décadas (cuadro 2) expresa justamente esta fuerte expansión de la ciudad hacia el Sur. Las expropiaciones ejidales para realizar estas obras fueron numerosas, mientras que la permuta permitió que el elegante fraccio- 
namiento residencial de El Pedregal se desarrollara sobre los ejidos de Tlalpan y San Jerónimo Aculeo.

\section{CUADRO 2}

Crecimiento de la población en las delegaciones del sur del Distrito Federal (1950-1980)

\begin{tabular}{|c|c|c|c|c|c|c|}
\hline \multirow[b]{2}{*}{ Delegaciones } & \multicolumn{4}{|c|}{ Número de habitantes } & \multicolumn{2}{|c|}{$\begin{array}{c}\text { Tasa de crecimiento } \\
\text { anual }\end{array}$} \\
\hline & 1950 & 1960 & 1970 & 1980 & $1960-1970$ & $1970-1980$ \\
\hline M. Contreras & 21955 & 40724 & 77442 & 173105 & 6.2 & 7.6 \\
\hline Tlalpan & - & 61195 & 135105 & 363974 & 7.5 & 9.2 \\
\hline Xochimilco & - & 70381 & 119073 & 217481 & 5.1 & 5.8 \\
\hline Tláhuac & - & - & 64451 & 146923 & - & 7.8 \\
\hline Milpa Alta & - & - & - & 53616 & - & - \\
\hline Total D.F. & 2931542 & 4833102 & 6963286 & 9373353 & & \\
\hline
\end{tabular}

Relacion

poblacion

delegationes

poblacion D.F.

\begin{tabular}{rrrrr}
$(0)(1)$ & 0.7 & 3.5 & 5.6 & 10.2 \\
\hline
\end{tabular}

Fuentes: Censos de Población y Vivienda.

Nota: La talsa de crecimiento anual de la población se calculó de la misma forma que en el (atactro i.

Algunas delegatciones no presentan intermation para algunos anos, porgue aun no estaban incorporadas a la Zona Metropolitanta

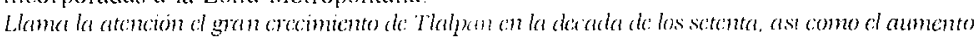

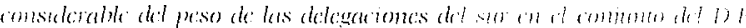

La Zona del Ajusco se urbaniz en los sesenta y sobre todo en los setent ${ }^{\circ} \rightarrow$ través de nuevos as. amientos para sectores medios Y popula $\_$. El análisis del surgirn iento y evolución de la zona urbana ejidal de San Nicolas Totolapan, ejemplifica en parte los comienzos de esa urbanización. ${ }^{5}$

Los documentos que hemos consultado en el archivo de la SRA, indican que en 1959 se demandaron nuevos solares urbanos para ubicar a los hijos de los ejidatarios que ya no tenían lugar en el pueblo. Se solicitaron 250 lotes en la parte sur del poblado, ya que sus

¿ Las zonas urbanas cjidales se crean, en general, a traves de una resolución presidencial, y están rescrvadas, en principio, como zonas habitacionales para los ejiclatarios. Sin embargo, ellas han servido de base para la formacion de muchas colonias populares sobre terrenos ejidales, en la z.MCM. Esto se explica a partir de la posibilidad que concede la legislación agraria pa ra que los solares que excedan las necesidades de los ejidatarios puedan ser vendidos a otras personas: los "avecindados". (Varlev, Ann, 1985). 
características topográficas y la cercanía con aquél eran ideales para crear la nueva zona urbana.

Pero desde el momento en que se comenzaron a marcar los linderos surgieron las irregularidades tanto por el cobro del deslinde como por la repartición de lotes a personas ajenas al ejido. Entre los documentos revisados se han encontrado muchísimas cartas en las que se solicitaba la intervención de las autoridades agrarias para que decidieran, en casos de litigio (que eran numerosos por ventas reiteradas del mismo lote), a quién se daba posesión de la tierra. Tam. bién se pedía el auxilio de la policía para evitar que continuaran las ocupaciones ilegales.

Así, a partir de la creación de la zona urbana se inició un proceso de especulación en la que intervinieron personas ajenas al ejido y hasta funcionarios del entonces Departamento de Asuntos Agrarios y Colonización (DAAC). Hacia tines de los años sesenta se presentaban acusaciones concretas por la venta ilegal de terrenos: acusaciones de un presidente del Comisario Ejidal contra su antecesor; de colonos contra el Comisariado, etc. También se denunciaba que un grupo de pobladores formó en 1969 una Unión de Colonos de la Colonia Pedregal, y bajo esta denominación encabezó un movimiento para apoderarse de solares urbanos.

A raíz justamente de todas las acciones ilegales desarrolladas en la colonia y de la conflictiva situación existente, los colonos solicitaron, a partir de 1976, la regularización de la misma. Así, en 1980, la Comisión para la Regularización de la Tenencia de la Tierra (CORETT) expropió una superficie de 28 hectáreas de la zona, con el fin de lotificar y dar titulación legal a favor de los ocupantes, para lo cual se indemnizó a los ejidatarios. Esta es en la actualidad la unica colonia (llamada Pedregal) que se ha regularizado en esta parte del Ajusco.

Resulta interesante destacar, como corolario de esta descripción, que una urbanización que comienza a partir de un acto legal se produce luego dentro de tal juego de conflictos por la tierra que termina siendo objeto de un acto de regularización, con lo cual se confirma lo señalado en algunas investigaciones ya mencionadas sobre el tema (Varley, A., 1985).

Además de los conflictos que se producen a partir del desarrollo de la zona urbana ejidal, aparecen en esta etapa nuevos enfrentamientos entre ejidatarios y hacendados.

Por ejemplo, en 1975, en terrenos que antes pertenecían a la familia De Teresa, se construyó un club deportivo denominado Jardines de Eslava, y los ejidatarios denunciaron que para esa construcción se habían invadido tierras de San Nicolás Totolapan y Padier- 
na. En 1980 vuelve a presentarse un conflicto (que aparece en los archivos de la SRA) por la posesión de 23 hectáreas, entre la familia De Teresa y los ejidatarios. Estos insisten en que los terrenos correspondían a la ampliación del ejido, lo cual es negado por los De Teresa.

Evidentemente, cuando los terrenos pedregosos que no tenian ninguin valor agricola, pueden ser usados para actividades urbanas, los conflictos por linderos se actualizan y los dueños de las haciendas, que al momento de las dotaciones y ampliaciones no prestaron mucha atención a esos trazados, vuelven a reclamar sus tierras, creándose nuevas zonas de conflicto.

También (aunque posiblemente en menor medida) aparecen enfrentamientos entre ejidatarios y el Estado. Se han detectado reclamos de ejidatarios afectados por expropiaciones a favor de empresas del Estado (la Compañía Federal de Electricidad), que no habian sido indemnizados.

Veremos cómo se completa este cuadro de enfrentamientos, conflictos y luchas, al estudiar de forma más detallada los asentamientos irregulares de la zona. Pero antes quisiéramos hacer referencia al desarrollo agrario actual del ejido, y a la situación de los ejidatarios, aspectos necesarios para precisar el complejo panorama de esta zona en transición (sobre todo de sus condiciones ambientales recientes), y para entender mejor el contexto en que se han dado las luchas de los colonos de los asentamientos irregulares.

En una entrevista realizada al presidente del Comisariado Ejidal de San Nicolás Totolapan, éste manifestó que el ejido cuenta actualmente con una zona boscosa, otra de sembradío, montes comunales y una zona de agostadero, donde se asentaron algunas de las colonias que presentaremos más adelante. En él habitan 450 ejidatr rios, algunos de los cuales cultivan maíz, papa, haba y avena forrajera (para los animales de carga) en las 500 hectáreas de terrenos de temporal, pero reconoció que los rendimientos eran muy bajos (media tonelada por hectárea) y que el ejido tendía a desaparecer porque "se obtiene más trabajando fuera de él, en los empleos urbanos". ${ }^{6}$ Las fábricas de hilados y tejidos, como se dijo, daban trabajo a pobladores de la zona, pero fueron cerrando en la década 1955-1965, por su retraso tecnológico y por la competencia de las fibras sintéti-

${ }^{6}$ En un informe sobre la situación actual del ejido elaborado por la Comisión Coordinadora de Desarrollo Agropecuario del D.F., se hace hincapié en la necesidad de dar atención técnica al ejido, en el que no se ha aplicado ningún programa agropecuario para ayudar a los campesinos a disminuir las pérdidas que han tenido por razones meteorológicas, plagas y enfermedades, falta de recursos materiales, etc. Se pierde, por esas razones, casi la mitad de los cultivos. 
cas (Durand, J., 1983); los ejidatarios entonces se emple an en otras industrias de la ciudad o en los servicios urbanos.

Por lo que se refiere a la explotación forestal el entre vis, tado expresó que el ejido había tenido un contrato con las fábricar s de papel Loreto y Peña Pobre, a través de la concesión que se les 'había otorgado (nota 4). Era la SRA la que fijaba el precio que es sa compañía

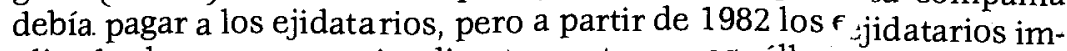
plicados lograron negociar directamente con aquéllar s y obtener mejores precios; sin embargo, aceptó que el pago era insuficiente, cubriendo sólo el salario de los trabajadores ("los, ejidatarios están regalando la madera"). ${ }^{7}$

El presidente del Comisariado Ejidal den' unciaba enfáticamente las "invasiones" de terrenos por los colone,s y a algunas autoridades que los apoyaban (autoridades agrarias, y delegacionales), atribuyendo en parte a esas ocupaciones la b'aja de la productividad de los terrenos agrícolas (aunque reconociós que las colonias se ubicaron en tierras de agostadero).

Resultó claro, de esta entrevista, que el Comisariado Ejidal veía a los colonos como sus mayores enemigos, a pesar de que también había tenido conflictos con otros; agentes sociales.

Las numerosas denuncias que han aparecido contra los comisariados por la venta de tie rras del ejido (que les ha permitido enriquecerse en los últimos años) y el obstáculo que las invasiones por parte de colonos pobres ?pueden significar para la concresión de esas ventas y la acumulación de dinero, explicarian la posición de las autoridades ejidales contra las colonias populares. Esta posición coincide asimismo con las prácticas represivas de algunos organismos del Estado con relación a los colonos, dadas las vinculaciones entre autoridades ejidales, el partido oficial y funcionarios públicos, lo cual no niega, a veces, la presencia de enfrentamientos entre estos últimos. ${ }^{8}$

7 En la Memoria de 1978-1982 de COCODA, ya citada, se decía que las fábricas Loreto y Peña Pobre deberian salirse del D.F. por sus grandes efectos contaminantes, y por el gran consumo de agua requerido. Ello im plicaba lógicamente cancelar la concesión sobre su aprovechamiento de los bosques del D.F., concesión que, ade:más, se derivó de una emergencia (a fin de evitar, por la guerra, la paralización de: las actividades de la fábrica) y tuvo un carácter povisional. La fábrica fue por fin clausurada en 1986.

${ }^{8}$ Cuando hablamos de los ejidos debemos hacer una diferenciación entre los (jidatarios y los miembros del Comisariado Ejidal; estos últimos han sicio los yne han vendido los terrenos con la tolerancia, en general, de las autoridades agrarias ( $\mathrm{Nu}$ nez, O., 1984). Sin embargo, tampoco existe una "unidad" permanente entre estos actores y ello se expresa en las declaraciones del presidente del Comisariado ljijial que hemos entrevistado. 


\section{Los asentamientos irregulares del Ajusco}

Continuando con el análisis de la urbanización de la zona, nos referiremos a las colonias que desde mediados de la década de los setenta comenzaron a formarse a la altura del $\mathrm{km} 7-8$ de la carretera panorámica Picacho-Ajusco, en los terrenos que se encuentran ubicados más arriba de la vía del ferrocarril a Cuernavaca y cercanos a la citada colonia Pedregal. Ellas suman actualmente 11, con aproximadamente 25000 habitantes y se han desarrollado, en parte, sobre terrenos correspondientes al ejido de San Nicolás Totolapan (121 hectáreas), en parte, sobre el ejido de San Andrés Totoltepec (sólo 15 hectáreas) y sobre propiedades en litigio de la familia De Teresa ( 89 hectáreas). Según manifestaron los colonos, ha existido una subdivisión, en cierta medida artificial, de algunas de estas colonias, promovida por las autoridades por razones políticas.

La población asentada ha provenido, en parte, de la provincia, pero sobre todo del D.F., en algunos casos a raíz de desalojos provocados por la realización de obras públicas, como los ejes viales. Según algunos estudios ${ }^{9} 62 \%$ de las familias ganaba en 1984-1985 menos del salario mínimo, $15 \%$ el salario mínimo y $15 \%$ de 1 a 1.5 ese salario. Asimismo, aproximadamente $36 \%$ de la población trabajaba en el sector secundario, sobre todo en la construcción, habiendo aumentado en los últimos años la desocupación, particularmente a partir de la crisis que afectó fuertemente a esa actividad.

En general, las colonias poseen viviendas bastante precarias, aun que la proporción de aquéllas construidas con materiales sólidos varía según el asentamiento. En cuanto a los servicios, cuentan con letrinas rudimentarias y la provisión de agua se realiza comúnmente a través de tambos, de donde salen mangueras que distribuyen el líquido, por gravedad, hasta las viviendas. Los equipamientos como escuelas, "kinder", centros de salud, existen sólo en algunas colonias, sobre todo en aquéllas donde la organización comunitaria ha sido más fuerte.

Aquí nos referiremos principalmente a las colonias Bosques, 2 de Octubre y Belvedere, que hemos tenido la oportunidad de conocer mejor, a través de entrevistas con pobladores o dirigentes de sus organizaciones, de documentos provistos por ellos mismos, o elaborados por grupos de apoyo formados por estudiantes y profesionistas que han estado colaborando con los colonos.

9 Nos referimos a datos obtenidos de una encuesta que se aplicó a los colonos y que constan en la tesis para optar al título de arquitecto, de Villegas, B., Pulido L. y Ávila, J.: Ajusco: conservación ecológica y desarrollo urbano, que estaba en proceso de finalización en 1985. 
El análisis de estas colonias, de sus organizaciones y luchas por mantenerse en el lugar, de sus enfrentamientos con ejidatarios, ex hacendados de la zona, y sobre todo instituciones del Estado, nos permitirá entender las transformaciones más recientes de la problemática socio-ambiental y sobre todo extraer algunas conclusiones con respecto a la continuidad de ciertos procesos históricos, y a las posibilidades de cambio que los sectores populares urbanos pueden esperar a partir de nuevas propuestas y movilizaciones.

\section{Las colonias Bosques, 2 de Octubre y Belvedere}

(Orígenes, organización y evolución socio-espacial)

Bosques fue la primera colonia que se asentó en la zona; los pobladores compraron las tierras a los ejidatarios de San Nicolás Totolapan, con los que resultó difícil ponerse de acuerdo en los precios. El asentamiento comenzó hacia 1975, y al año siguiente existieron tres intentos de desalojo, según los colonos, por parte de ejidatarios y policias disfrazados. Como no se consiguió desalojar a la población se propuso su reubicación en los basureros de Santa Cruz Meyehualco.

Bosques ha pasado por varias etapas organizativas. Al principio la colonia estuvo controlada por la Confederación Nacional de Organizaciones Populares (CNOP), la cual se alió a Francisco de la Cruz (conocido líder de una colonia popular, que terminó en prisión); esto generó una serie de conflictos y un gran descontento entre los pobladores, a partir del cual surgió una nueva directiva que desembocó en el Consejo General de Representantes, organización democrática, independiente de partidos políticos, con una amplia participación de los colonos a través de sus representantes de manzana o sector.

La colonia 2 de Octubre, por su parte, se ubica en gran medida sobre el mismo ejido que la anterior, pero una parte corresponde a la mencionada zona en litigio de la familia De Teresa.

En 1977 existieron rumores de desalojo de los pobladores y éstos comenzaron a organizarse constituyendo en 1978 la Unión de Colonos, a través de la cual se iniciaron gestiones para regularizar la tenencia de la tierra, solicitando asimismo un amparo federal para protegerse contra los desalojos, pero sin éxito. Efectivamente, a fines de 1979 fueron desalojados y quemadas sus casas ubicándose los pobladores al lado de las vías del ferrocarril, en viviendas aún más precarias, donde permanecieron dos años. En 1980 recibieron un amparo de la justicia y en vista de que sus anteriores terrenos 
comenzaron a ser vendidos por medio de una inmobiliaria, decidieron volver a instalarse en ellos a comienzos de 1981. Pero el 2 de octubre de 1981 se los vuelve a desalojar violentamente y se queman 200 viviendas. A pesar de los daños físicos y psíquicos sufridos por la población en este acto de violencia y represión, los colonos decidieron quedarse en el lugar y reconstruir nuevamente sus viviendas.

El presidente del Comisariado Ejidal de San Nicolás Totolapan reconoció, al ser entrevistado, que ellos habían quemado esas viviendas, porque estaban ubicadas en terrenos correspondientes a su ejido, que los colonos habían invadido.

No obstante las agresiones de que ha sido objeto, la colonia 2 de Octubre logró consolidar su organización y realizar también una serie de obras de mejoramiento que fueron el producto del esfuerzo y el trabajo colectivo de sus habitantes.

En cuanto a la colonia Belvedere, su historia es un poco diferente y más compleja que las anteriores. Se asentó sobre terrenos en litigio y ello significó una serie de enfrentamientos con agentes inmobiliarios, propietarios y organizaciones o individuos vinculados al partido oficial, que complicaron e hicieron más difícil el proceso de ocupación de la zona y la formación de una organización representativa de la mayoría de los pobladores.

Los terrenos en litigio provienen de los conflictos entre ejidatarios y hacendados por el trazado de los límites entre los diferentes tipos de propiedad y que, como ya dijimos, se actualizan con el proceso de urbanización y los nuevos usos que pueden darse a los terrenos.

Hacia 1976-1977 la familia De Teresa constituyó "Belvedere Asociación Civil" para edificar en lo que dice son sus terrenos, una colonia modelo. Sin embargo, parece ser que debido a las invasiones que se estaban produciendo en esta zona decidió concesionar para su venta (un espacio de 300 lotes de $200 \mathrm{~m}^{2}$ cada uno) a una lideresa - vinculada al partido oficial- y a otras personas con experiencia en acciones inmobiliarias especulativas y fraudulentas.

Por otra parte, a principios de 1980, también la Inmobiliaria Rena comenzó a vender en la zona sur-poniente que se yuxtapone al fraccionamiento antes citado. ${ }^{10}$ Como los terrenos estaban en liti-

10 La Inmobiliaria Rena parece estar vinculada a la historia de la fábrica de hilados y tejidos La Palma Montañesa que quebró alrededor de 1940, adjudicando como indemnización una parte de sus terrenos a los obreros sindicalizados; su secretario vendió parte de los mismos a Inmobiliaria Rena, en la que aparece un abogado, Gastón Alegre. Ella vende terrenos en varias zonas de Tlalpan. Ver, "Plan de Desa- 
gio, las ventas fueron fraudulentas, usando asimismo métodos violentos para asegurarse los pagos de los colonos; aquéllos incluyeron frecuentemente desalojos, para luego volver a vender los lotes.

Los colonos más conscientes crearon en 1981 la Comisión Promotora Independiente, la cual llegó a proponer la suspensión de pagos, denunciando asimismo el fraude ante las autoridades. Sin embargo las agresiones continuaron hasta lograr el desalojo masivo de los habitantes, en el que se produjeron fuertes actos de violencia. La Asociación de Colonos-Casa del Pueblo, que constituyó una organización más consolidada de los pobladores, consiguió un amparo administrativo y logró reinstalar a los desalojados en diciembre de 1982.

Al avanzar el poblamiento, como en los otros dos casos, los mismos colonos se proporcionaron equipamientos indispensables consiguiendo luego el apoyo oficial de la Delegación, la Secretaría de Educación, y Salubridad.

En 1984 la Asociación de Colonos logró que se ordenara la suspensión de pagos a los fraccionadores, hasta no determinar quiénes eran los auténticos dueños de la tierra, ya que aquélla descubrió, al revisar al registro público de la propiedad, que no existía ningún documento que acreditara a la familia De Teresa como propietaria de la zona. En esa época la Asociación agrupaba a la mayoría de los colonos; pero hacia comienzos de 1985 comenzó a desmembrarse, en parte, por la acción represiva y divisionista del Estado.

Los colonos entevistados expresaron, en general, que "ante la ineficiencia del argumento de la ilegalidad de las tierras para conseguir el desalojo, se acusó a los habitantes de estar contaminando la zona, argumento más político que real ya que la propia Delegación permitía la tala de los bosques e instalaba un basurero a corta distancia de las colonias".

Los planes oficiales para preservar el medio ambiente y los intentos de desalojo de las colonias del Ajusco. Respuestas de los pobladores.

El tema de la protección ambiental fue cobrando particular importancia dentro de las preocupaciones de los planificadores urbanos. Se hizo presente en una serie de planes que se propusieron en los últimos años de la administración anterior, y aún con mayor fuerza durante la actual.

Dentro de esos planes figuran el Ecoplan del Distrito Federal,

rrollo para la Colonia Belvedere", documento preparado por pobladores de la colonia con el apoyo de estudiantes y profesores de la Escuela de Arquitectura (Autogobierno). UNAM, 1984. 
el Plan General de Desarrollo Urbano del D.F., (aprobado en 1980), del cual se deriva el Plan Parcial de la Delegación Tlalpan, y el Plan Ecológico del D.F. (de 1983).

En el Plan General de Desarrollo Urbano del D.F., se establecía un área de conservación ecológica, donde sólo podrían desarrollarse usos agropecuarios, forestales y parques nacionales o metropolitanos; una zona de amortiguamiento o de transición, en la que se podrian establecer usos restringidos, compatibles con la conservación y el mejoramiento ecológico y una zona de desarrollo urbano destinada a usos y actividades urbanas y su crecimiento futuro. El área de colonias del Ajusco se encuentra ubicada en la zona definida como de amortiguamiento, y por lo tanto su permanencia sería incompatible con la política de mantener el equilibrio ecológico del sur de la ciudad.

Los demás planes coincidirían en preservar la zona de amortiguamiento de asentamientos humanos deteriorantes del medio ambiente. Con base en esa serie de planes se realizó en agosto de 1983 un dictamen pericial que llegó a la conclusión que efectivamente no debían existir asentamientos humanos en esa zona de amortiguamiento "ya que obstaculizan el equilibrio ecológico del D.F., por ser la sierra del Ajusco una de las pocas áreas importantes de oxigenación del D.F.".

Reafirmando esa posición, la propuesta del "Programa de Reordenación Urbana y Protección Ecológica del D.F." (PRUPE), dado a conocer hacia fines de 1984, establecía la estricta fijación de límites al crecimiento de la zona urbana y pretendia declarar 77000 hectáreas como área de reserva natural. Se incluía dentro de esta zona de reserva a toda la sierra del Ajusco y en ella se llevaría a cabo un control estricto para evitar nuevos asentamientos, para promover la reforestación, eliminar las plagas de los bosques, evitar la erosión de los suelos, etc. Esta zona sería propiedad del D.D.F., utilizando guardas ecológicos estratégicamente distribuidos para asegurar el mejoramiento ambiental. El carácter represivo y utópico de este plan salta a la vista, así como el desconocimiento de la situación de los espacios rurales que se encuentran al sur del D.F.

Las grandes críticas que este plan ha recibido condujeron a la elaboración de nuevas versiones del mismo; sin embargo, en su momento, lograron hacer aún más dura la posición oficial (al menos por una parte de los funcionarios públicos) contra la permanencia de las colonias populares del Ajusco.

En general, las propuestas y planes mencionados sirvieron de fundamento a las autoridades para intentar el desalojo de la población de esas colonias, a través de actos de violencia y represión, in- 
tentos de negociación y ofertas de relocalización. ${ }^{11}$ Sin embargo, las colonias más combativas lucharon por mantenerse e incluso por mejorar las condiciones de vida en esa zona.

Desde el punto de vista ambiental, comenzaron a aplicar planes de reforestación, huertas familiares, buscando además nuevas alternativas para evitar la contaminación. Contaron con el apoyo de grupos universitarios y movimientos ecologistas, para la elaboración de programas de protección ambiental, y sobre todo para defender su permanencia en la zona y ofrecer al mismo tiempo nuevas alternativas y planes para el futuro.

Un gru po de biólogos de la Universidad Nacional Autónoma de México (Grupo Interdisciplinario de Estudios Agrobiológicos) después de estudiar la zona consideró en un documento presentado (GIEA, 1984) que "la población de esas colonias causa poco perjuicio al ambiente, de por sí ya contaminado por las industrias, los automóviles, así como por la tala excesiva y nula repoblación de árboles, causado por compañias que explotan los bosques para la producción de papel o muebles, bajo el único interés de la ganancia". También denunciaba la instalación de un basurero por la delegación Tlalpan, que contenía gran cantidad de materiales no biodegradables y material orgánico, que contaminaban los acuiferos; la contaminación que producían era muchísimo mayor que la que podrian generar las colonias populares.

El contenido de este documento, resume, en cierta medida, cuáles son las causas y los agentes de la degradación de la zona que hemos venido presentando a través del análisis histórico, y enfatiza el contenido clasista de los procesos socio-ambientales y de ciertas políticas oficiales, en desmedro de los estratos pobres de la sociedad urbana.

Sin embargo, las movilizaciones de los pobladores, $y$ los apoyos de los diferentes grupos mencionados, provocaron un cambio en la actitud de la administración, con respecto al destino de estas colonias.

En mayo de 1984 apareció el "Programa de Conservación del

11 En la sintética presentación que hemos hecho sobre la formación de las colonias y acerca de las luchas de sus pobladores, no hemos podido detallar la participación de diferentes agentes en los intentos de desalojo que se han repetido, por lo menos para las tres colonias que tuvimos la oportunidad de conocer con mayor profundidad. En las entrevistas a los dirigentes de las mismas, se nos ha comunicado que los intentos de desalojo (quema de viviendas y otros actos de violencia) tuvieron siempre el apoyo de autoridades delegacionales, aunque fueran alentadas o promovidas por el Comisariado Ejidal, o la familia De Teresa. También se nos comunicó que en algunos momentos las tácticas empleadas incluyeron intentos de "compra" de líderes, para que indujeran a los colonos a dejar la zona o aceptar una relocalización en condiciones muy desventajosas. 
Ajusco" en el que por primera vez se aceptó oficialmente que no habría desalojo masivo de los pobladores de las colonias; se anunció la expropiación de la zona de viviendas y la regularización de los colonos con antigüedad suficiente para justificar su permanencia.

En un documento presentado por el delegado de Tlalpan en diciembre de 1984 se reiteraron aspectos incluidos en el programa anterior, agregando que al tratarse de colonias ecológicas no se dotarían de servicios públicos "regulares" sino de servicios "rústicos y campestres" que no alteren el equilibrio ecológico.

Estas propuestas que aparecían corno iniciativas del gobierno, no hacian sino incorporar y hacer suyas, muchas de las iniciativas que habían venido desarrollando los mismos pobladores con el auxilio de los grupos voluntarios.

A comienzos de 1985, coretr y la delegación de Tlalpan pusieron en marcha el programa de regularización de la tenencia de la tierra, que consistía en llevar a cabo una identificación de los lotes y un censo de la población, así como en la entrega de documentos individuales acreditando la residencia de los pobladores en la zona. Las tierras no habían sido expropiadas, y los documentos estaban muy lejos de constituir títulos de propiedad; no obstante, las colonias más combativas aceptaron el comienzo de la regularización, conscientes de que debían seguir presionando y luchando para que el proceso continuara.

Pero en 1986 comenzó a operar el "desalojo por vía económi$\mathrm{ca}^{\prime}$, a través del alto costo que se exigía por el metro cuadrado de terreno que se iba a regularizar.

Para luchar en contra de ese "desalojo" las colonias han formado recientemente una coalición, estableciendo convenios con los ejidatarios y logrando una disminución de los precios mencionados. (Mena, J., 1987).

Propuestas alternativas de colonos y técnicos

Aunque en las tres colonias que venimos analizando se han estado llevando a cabo tareas de reforestación, experimentando huertos familiares, analizando o probando la posibilidad de usar sistemas alternativos para el tratamiento y reciclaje de deshechos orgánicos que no contaminen, es en la colonia Bosques donde se ha avanzado más en la elaboración de un proyecto ecológico integrado y en el desarrollo de las tareas previas a su aplicación. La propuesta de "Colonia Ecológica Productiva", proviene del trabajo mancomunado de la organización de colonos y de grupos de técnicos independientes que colaboran con los mismos, pero también se ha presentado a organismos públicos competentes (Departamento del D.F., Delegación 
de Tlalpan) con objeto de obtener su apoyo y el financiamiento necesarios para la puesta en práctica del mismo. Sin embargo, ninguna dependencia gubernamental ha apoyado el proyecto.

La implementación de este programa implicaría, entonces, una acción concertada entre diferentes sectores, pero no podría existir sin la infraestructura organizativa de la colonia, consolidada en siete años de auto-gestión comunitaria.

El documento que contiene la propuesta ${ }^{12}$ comienza por criticar el enfoque conservacionista del Departamento del D.F. que a través de sus planes propone para el Ajusco un gran parque nacional, un pulmón para la ciudad de México, que se origina en el modelo de "cinturón verde" utilizado por el urbanismo de principios del siglo, separando así la necesidad de reforestar, de la producción.

En cambio, ella concibe a la población de la colonia no como marginada sino como "potencialmente productiva", en una zona urbano-rural (en transición) donde pueden conjugarse valores del campo y la ciudad.

Se propone que el espacio de consumo no sea predominante, recuperándose así un espacio de "práctica social productiva". Relacionado con éste se piensa crear un nuevo modelo productivo que pueda generar productos "socialmente necesarios, económicamente viables y en una forma ecológicamente válida", mediante un proceso educativo de la comunidad.

Ya se han comenzado a implementar en la colonia Bosques algunos "pilotos productivos"; el Comité de Salud ya produce ciertos medicamentos básicos como, por ejemplo, ungüentos y jarabe para tos y ha impartido varios cursos de nutrición (preparación de soya y otros). También se tienen instalados sistemas de reciclamiento de residuos; están operando desde 1985 tres unidades SIRD()-seco y se está construyendo un siRDo-húmedo para 120 familias. ${ }^{13}$ La produc-

12 El documento titulado "Colonia Ecológica Productiva", fue elaborado por el Grupo Cooperación Ajusco, del que forman parte el Consejo General de Representantes, A.C. y la Sociedad Cooperativa de Consumo Bosques del Pedregal en Lucha; el Grupo de Tecnología Alternativa, S.C., el Centro de Investigación Biológica, S.C. y Agro-Industria Integrada, S.A.; los tres últimos son grupos de profesionistas independientes que trabajan fundamentalmente para organizaciones populares.

13 El SIRDO húmedo que se aplica en este proyecto, es un sistema de reciclamiento de deshechos líquidos y sólidos provenientes de la vivienda o de equipamientos como mercados, panaderías, etc. Produce un abono orgánico de excelente calidad, aguas clarificadas aptas para ser empleadas para piscicultura y aguas filtradas para riego hortícola o frutícola. Con este sistema, se evita la contaminación generada por los mencionados deshechos y se consigue, al mismo tiempo, la participación de la comunidad en su reciclaje. (Para mayor información sobre este sistema ver en este mismo número de la Revista la nota de Josefina Mena). 
ción de plantas medicinales y hortalizas cuenta con varios pilotos y con un grupo de promotores comunitarios.

La idea es que cada módulo produzca elementos que sirvan para otro y viceversa, lo que implica buscar complementariedades entre procesos de producción, utilizando residuos como un insumo y reduciendo al mínimo los impactos sobre el medio ambiente. Por ejemplo, el abono producido por el sIRDo serviría para los árboles frutales y al mismo tiempo las ramas y hojas secas que pueden provenir de esos árboles sirven para el siRDo; el excremento del módulo de cría de conejos puede utilizarse para la producción de hortalizas y también para el sIRDo.

El proyecto constituye, sin duda, un ejemplo de búsqueda de nuevas alternativas para el mejoramiento de la comunidad, mostrando al mismo tiempo la importancia de la organización independiente de los pobladores y de las luchas urbanas para ofrecer nuevas soluciones a la problemática urbana y ambiental.

\section{Conclusiones}

Este trabajo ha mostrado cómo se ha ido ocupando una zona de relevancia ecológica para la ciudad de México, destacando el contenido social de esa ocupación y su relación con la degradación del medio ambiente.

Así, a través de la presentación y discusión del caso del Ajusco, se han ejemplificado los mecanismos que se ponen en juego y los agentes que actúan en los procesos de apropiación del suelo, tanto en la etapa anterior a la gran expansión metropolitana, como en las últimas décadas, cuando ella ya comienza a afectar los espacios del sur del Distrito Federal.

Con relación a esta última etapa, el análisis de caso se ha centrado en las formas de urbanización de terrenos ejidales, especificando los orígenes y desarrollos diferenciales de colonias populares surgidas en épocas distintas, e ilustrando asimismo lo que en la primera parte del trabajo se había expuesto de manera global para la zмсм. Los datos aportados también confirman lo enunciado por otros investigadores (Azuela, 1987), en el sentido de que la urbanización de los ejidos está regida, en cierta medida, por las autoridades de organismos oficiales vinculados a la cuestión agraria, al mismo tiempo que los núcleos agrarios no desaparecen y siguen influyendo en la organización de las colonias.

El estudio ha puesto igualmente de manifiesto la continuidad en el tiempo de los procesos de apropiación y lucha por la tierra y ha evidenciado que los fenómenos actuales no pueden entenderse 
sin una perspectiva histórica. Por ejemplo, la venta de tierras a los colonos por parte de los ejidatarios no tendría una explicación completa si, además de la situación actual de enfrentamiento entre producción campesina y urbanización, no se hace referencia a las condiciones del reparto agrario, que sólo permitió a los campesinos acceder a tierras de mala calidad, en general poco aptas para el cultivo. Tampoco pueden entenderse los nuevos conflictos entre propietarios privados y ejidatarios si no se consideran las luchas entre hacendados y campesinos, antes y durante el proceso de reforma agraria. Ha quedado claro a partir de esas referencias históricas por qué existen las llamadas "zonas en litigio", que afectan las luchas recientes de los habitantes de las colonias populares asentadas sobre las mismas; ellas provienen de la actualización de enfrentamientos como corolario de una nueva valorización de terrenos que hoy son requeridos como soporte de actividades urbanas.

Pero el énfasis del trabajo se ha puesto en la relación entre los procesos y conflictos por la tierra y la cuestión ambiental, vista también en una perspectiva histórica. Si bien el punto de referencia más importante ha sido la actual problemática socio-ambiental que se ha generado en la zona en estudio, a raíz del intento de desalojo de colonos pobres asentados allí desde hace más de diez años, los aspectos históricos que hemos ido presentando han permitido apoyar los reclamos de pobladores y técnicos que colaboran con los mismos, mostrando la arbitrariedad de algunos argumentos oficiales esgrimidos.

Hemos visto cómo la tala de bosques, la abusiva explotación de madera, el agotamiento de manantiales y el deterioro de los suelos para cultivo, habían comenzado a partir de las prácticas de hacendados y propietarios de fábricas instaladas en el Ajusco, mucho antes del inicio de la urbanización de la zona. La degradación de la misma se acentuó notablemente cuando, hacia fines de los cuarenta, se concesionó la explotación de bosques a la fábrica Loreto y Peña Pobre, con lo cual se redujeron los linderos del parque nacional creado en la administración cardenista.

Es, entonces, dentro de este contexto de avanzado deterioro ecológico, que principia la urbanización de los ejidos y ocupa, en gran medida, terrenos no aptos para cultivos, ni boscosos, como lo había reconocido el mismo presidente del Comisariado Ejidal entrevistado, a pesar de su contradictoria posición con relación a los colonos y a los demás agentes actuantes en la zona.

Poner en contexto histórico la situación ambiental del Ajusco y relativizar los impactos ecológicos de la urbanización popular, no significa defender cualquier forma de expansión desmedida de la 
ciudad. Hemos presentado y apoyado algunas propuestas de desarrollo urbano alternativo (como la colonia ecológica productiva) porque representan un tipo diferente de ocupación del espacio, que no implica necesariamente la destrucción del medio "natural" o productivo, como la ocurrida a través de la expansión de la zMCM en las últimas décadas, y que hemos descrito en la primera parte de este trabajo.

Asi, a pesar de las dificultades que pueden encontrarse para el desarrollo de propuestas de ese tipo ${ }^{14}$ sería necesario que las experiencias basadas en las mismas se multiplicaran en el futuro, constituyendo formas más difundidas de gestión urbana, sobre todo para los sectores más desfavorecidos de la sociedad. Estos modelos alternativos de urbanización dificilmente podrian surgir a partir de prácticas inmobiliarias, marcadas por la lógica de la ganancia, ni de formas burocráticas centralistas (Bosquet, M., 1980), sino de las organizaciones de pobladores y de la auto-gestión comunitaria, que debe necesariamente contar con el apoyo de políticas adecuadas del Estado.

$\mathrm{El}$ análisis y vinculación de aspectos sociales y físico-ambientales del crecimiento urbano, utilizando una variada información (que en general no suele relacionarse) proveniente de fuentes muy diversas, ha intentado superar los enfoques simplistas predominantes en el estudio de esos fenómenos. Sin embargo, estamos conscientes de que son necesarias muchas más investigaciones dentro de la perspectiva que hemos tratado de desarrollar, para poder profundizar en el conocimiento de las relaciones señaladas y en la explicación de los procesos urbano-ambientales.

14 También en la nota de Josefina Mena, que se incluye en este número de la Revista, se hace una evaluación de los problemas y dificultades que existen para el desarrollo de estos proyectos y la aplicación de tecnologias alternativas. 


\section{Bibliografía}

Azuela, Antonio, "The law and the outlawed city. Low income settlements and the law in Mexico City", International Journal of Urban and Regional Re search (por aparecer)

Bosquet, Michel (Andre Gorz), Ecología y libertad, (técnicas y lucha de clases), Ed. Gustavo Gili, Colección Tecnología y Sociedad, Barcelona, 1980.

Campbell, Timothy, "Resource Flows in Urban Ecosystem; fuel, water and food in Mexico City", 1981 (mimeo).

Comisión Coordinadora para el Desarrollo Agropecuario del Distrito Federal, Memoria 1978-1982, Departamento del Distrito Federal, México, 1982. Los maniferos de la sierra del Ajusco, varios autores, México, 1980

Cruz, Ma. Soledad, "El ejido en la urbanización de la Ciudad de México", tesis profesional-UAM (Azcapotzalco), 1981.

Durand, Jorge, La ciudad invade al ejido, Edición de la Casa Chata 17, México, 1983.

Grupo Interdisciplinario de Estudios Agrobiológicos (GIEA), Consideraciones técnicas sobre la supuesta contaminación provocada por algunas colonias del Ajusco, Facultad de Ciencias (Biología), UNAM, 1984. (mimeo).

Grupo Cooperación Ajusco: "Colonia Ecológica Productiva", México, 1985. (mimeo).

Ibarra, Valentín, Sergio Puente y Martha Schteingart, "La ciudad y el medio ambiente", Demografía y Economía, voi. xvilı, núm. 57, 1984.

Lugo M.L. y F. Bejarano, "La acción del Estado, el capital, y la formación de las colonias populares en la transformación urbana de las tierras ejidales de las delegaciones de Magdalena Contreras y Tlalpan. El caso de la colonia popular Miguel Hidalgo", tesis profesional, Universidad Iberoamericana, México, 1981.

Mena, Josefina, "La reivindicación ecológica-productiva del movimiento urbano popular en la Zona Metropolitana de la Ciudad de México", México, 1987, (mimeo).

Núñez, Óscar, "Péripherie urbaine et intervention étatique à México", en: Pratiques Urbaines 2, CEGET-CNRS, Francia, 1984.

Reyes, Alfonso, Ajusco, mirador de México, CocoDA, DDF, 1981.

Schteingart, Martha, "Crecimiento urbano y tenencia de la tierra. El caso de la ciudad de México", en: Revista Interamericana de Planificación, voi. xv, núm. 60, 1981 (a)

"Formación y consolidación de un asentamiento popular en México. El caso de Ciudad Nezahualcóyotl", Revista Interamericana de Planificación, vol. xv, núm. 57, 1981 (b).

Varley, Ann, "La zona urbana ejidal y la urbanización de la ciudad de México", Revista A (UAM Azcapotzalco), voi. II, núm. 15, 1985.

Villegas, B., L. Pulido y J. Ávila, "Ajusco: conservación ecológica y desarrollo urbano", tesis para optar al título de arquitecto, Escuela de Arquitectura (Autogobierno), unaM, México, 1985. 
, 